\title{
OS POVOS TRADICIONAIS E O MITO DO CRESCIMENTO ECONÔMICO EM HARMONIA COM DESENVOLVIMENTO SUSTENTÁVEL: UMA CRÍTICA À LUZ DA DOUTRINA PROTECIONISTA DO MEIO AMBIENTE
}

Carla Vladiane Alves Leite

Doutoranda em Direito pela PUC/PR. Bolsista pela FAPEAM. Mestre em Direito Ambiental pela Universidade do Estado do Amazonas - UEA. Especialista em Direito Penal e Processual Penal pelo Centro de Ensino Superior do Amazonas - CIESA. Especialista em Direito do Trabalho e Previdenciário pelo Centro de Ensino Superior do Amazonas - CIESA. Advogada. Graduada em Direito pela Universidade Luterana do Brasil-ULBRA/AM. E-mail: carla_vladiane@hotmail.com / cv_advocacia@hotmail.com

José Querino Tavares Neto

Professor Associado da Faculdade de Direito da Universidade Federal de Goiás e do Programa de Pós-Graduação da PUCPR. Pós-doutor em Direito Constitucional pela Universidade de Coimbra com bolsa da Capes. Consultor das Faculdades Atenas de Paracatu e Bolsista de Produtividade da Fundação Araucária. josequerinotavares@gmail.com

\section{Resumo}

Nos últimos anos os impactos do desenvolvimento econômico sobre o ambiente natural intensificaram-se de maneira geométrica em um âmbito mundial da problemática do esgotamento de recursos e devastação do meio ambiente para se adquirir matéria prima, colocando em risco os ecossistemas que sustentam todas as dinâmicas da humanidade, principalmente os povos tradicionais que habitam nesses lugares. Essa realidade não é recente, tendo sido alvo de discussóes desde o inicio do século passado. Por conta disso, a complexidade e a urgência das questóes ambientais levaram a comunidade global a unir esforços a fim de estabelecer uma nova perspectiva e novos caminhos para o desenvolvimento sustentável ambiental, a qual pudesse fazer conviver em harmonia a necessidade de se desenvolver econômica e socialmente, porém com o direito a uma vida saudável e ambientalmente protegida, já que se trata de um bem fundamental a dignidade da pessoa humana, reconhecido no mundo todo. Para isso, novas politicas públicas estão sendo implantadas e muitas das antigas estão sendo revistas. Diante da importância da problemática que o debate suscita, o presente trabalho pretende fazer um estudo acerca das 
reflexóes doutrinárias envolvidas do tema à luz do direito difuso e à proteção dos povos tradicionais. Para tanto, observar-se-á a evolução do conceito, suas esferas e perspectivas doutrinárias e jurídicas frente a uma legislação protecionista internacional do Direito Ambiental e dos povos tradicionais.

\section{Palavras-chave}

Desenvolvimento; Sustentabilidade; Meio Ambiente; Povos Tradicionais; Políticas Públicas.

\section{Abstract}

In recent years the impact of economic development on the natural environment intensified geometric way in a world of problematic context of resource depletion and devastation of the environment to acquire raw material, endangering the ecosystems that sustain all the dynamics of humanity, especially the indigenous peoples that inhabit these places. This reality is not new, having been the subject of discussion since the beginning of the last century. As a result, the complexity and urgency of environmental issues have led the global community to work together to establish a new perspective and new ways for the environmental sustainable development, which could do live in harmony the need to develop economically and socially But with the right to a healthy and environmentally protected life, since it is a fundamental right to human dignity, recognized worldwide. For this, new public policies are being implemented and many of the old are being revised. Given the importance of the issue that raises debate, this paper intends to make a study of the doctrinal considerations involved theme in the light of diffuse rights and the protection of traditional peoples. Therefore, it will be observed the evolution of the concept, his balls and doctrinal and legal perspectives front of an international protective legislation Environmental Law and traditional peoples.

\section{Key words}

Development; Sustainability; Environment; Traditional Peoples; Public Policy.

\section{Introdução}

Com o passar dos anos, os problemas ocasionados pela utilização inconsequente e pela falta de consciência de reutilização e reinserção dos recursos naturais foram se alastrando e tomando proporçóes alarmantes.

A humanidade só passou a ter consciência de que os bens naturais teriam sua finidade muito após o inicio da degradação do meio ambiente, o que fez correr com ideias 
para resolver ou ao menos diminuir os problemas ambientais já presentes em todo o planeta terra.

A partir da necessidade de se preservar o meio ambiente, conceitos sobre sustentabilidade e questionamentos se iniciam para resolver um dilema que ainda é necessário de resolução: a necessidade de harmonizar o crescimento econômico e a preservação do meio ambiente.

A comunidade global passou a partilhar reflexóes sobre um novo paradigma de desenvolvimento e crescimento econômico baseado em preceitos sustentáveis para o próprio ecossistema e para a humanidade como um todo. Para isso, esforços de varias partes do planeta se mobilizaram e questôes têm sido trazidas à discussão em vários fóruns de debates, dentre elas a questáo de ambientes que habitam povos tradicionais.

Dessa forma, o presente estudo vem trazer a análise dos conceitos de crescimento econômico no aspecto de desenvolvimento e sustentabilidade do meio ambiente.

Nessa perspectiva de discussão da complexidade de questóes ambientais, vem tratar de ambientes atingidos por esses termos de crescimento e desenvolvimento econômico em ambientes envolvendo os povos tradicionais e sua relação com a sociedade como um todo, trazendo o chamado Direito Socioambiental.

Serão consideradas as relaçóes da economia emergente, a preservação ambiental e o respeito aos povos tradicionais em face do paradigma de sustentabilidade por meio de bases teóricas do direito interno e internacional que tratam da problemática em questão, além das dificuldades de implantação dos preceitos harmônicos envolvidos.

Com esse objetivo do presente artigo adotou-se o método de abordagem dedutivo, articulado à documentação indireta e à pesquisa bibliográfica a partir de livros, periódicos, artigos em revistas especializadas, além dos veículos virtuais compatíveis.

\section{A Questão do Crescimento Econômico e do Desenvolvimento}

A partir do século XIX a Europa passou a ser o modelo para o resto do mundo e sua supremacia se espalhou e se consolidou através da burguesia europeia no mundo todo.

O homem burguês, que tinha a ideia de acumulação de riquezas através do individualismo, veio desenvolver um sistema econômico para proteger e garantir seus bens e status.

Tendo como marcos inicial a revolução industrial e a revolução francesa, a preocupação tornou-se a produtividade, o lucro, a "dominação" da natureza de forma indiscriminada, o crescimento econômico como base do desenvolvimento, apresentando como finalidade primordial a acumulação de riqueza. 
Essa burguesia se prevalecia, pois tudo podia em relação aos coloniais e proletários, por meio de um modelo político autoritário, centralizador, repressivo e desigual.

Como consequência, o resultado de toda essa dominação em busca das riquezas foi a destruição do planeta.

Herdamos um ambiente fragmentado, mutilado e estéril pela lógica de um sistema de produção que não vê a natureza como parte de nós e que pouco se preocupa com sua destruição, cuidando apenas para que o Paraíso daqueles que o comandam esteja garantido, tendo, portanto o mundo de ricos e pobres em grandes contrastes.

Com isso, passamos de um modo de produção para um modo de depredação do planeta todo e de seus recursos naturais, pois o sistema passou a ser não só explorador da força de trabalho, mas aniquilador do trabalhador, destruidor da natureza, uma 'fábrica de necessidades' que confunde, convenientemente, qualidade de vida com quantidade de coisas compradas.

Neste contexto, a proteção jurídica do meio ambiente passou ater caráter urgente e emergente e iniciou-se a partir do momento em que a degradação do planeta passou a ameaçar não só a qualidade da vida, mas a própria sobrevivência dos seres vivos, constatando-se a limitação, quantidade e existência, dos recursos naturais, e, por conseguinte, a necessidade, cada vez maior, de seu manejo adequado e racional, assim como dos resíduos gerados nos processos que envolvem sua utilização, como afirma PORFIRIO JUNIOR (2002: p.28-32), que vem a repensar vários conceitos, entre eles o do próprio desenvolvimento.

Por isso, os fóruns e as discussóes em reverter tais problemas iniciaram e colocou-se em cheque a ideia de desenvolvimento visando somente o aspecto quantitativo, tal como preconizado pela imensa maioria dos economistas entre os anos 1950 e 1970.

As discussóes foram tão grandes e que chegaram a conceitos para diferenciar desenvolvimento da ideia de crescimento econômico, o que ganhou força principalmente a partir da publicação do primeiro "Relatório do desenvolvimento Humano", em 1990, onde a ONU passou a divulgar anualmente um índice de desenvolvimento que não se resumia ao Produto Interno Bruto (PIB) per capita ou à renda por trabalhador, passando a enfatizar informaçóes como expectativa de vida, mortalidade infantil e outros indicadores de qualidade de vida.

Portanto, o aspecto qualitativo e inclusivo do que seria desenvolvimento foi se implementando e ganhando força no decorrer dos anos e teve suas bases revistas para diminuir cada vez mais os impactos da ganância no meio ambiente.

Nas palavras de FURTADO (2004, p.484):

[...] o crescimento econômico, tal qual o conhecemos, vem se fundando na preservação dos privilégios das elites que satisfazem seu afã de 
modernização; já o desenvolvimento se caracteriza pelo seu projeto social subjacente. Dispor de recursos para investir está longe de ser condição suficiente para preparar um melhor futuro para a massa da população. Mas quando o projeto social prioriza a efetiva melhoria das condiçóes de vida dessa população, o crescimento se metamorfoseia em desenvolvimento.

SACHS (2009, p.47-61) enfatiza que o desenvolvimento vai além do crescimento econômico, do mercado, da superação norte-sul, da economia ecológica, entre outros. Em trabalhos realizados em 2002 e 2004, o autor salienta que desenvolvimento envolve também a ideia de aspectos qualitativos essenciais que possam estimular os indivíduos a desenvolverem suas capacidades, seus talentos, criatividade e imaginação na busca da auto realização e da felicidade, mediante esforços individuais e coletivos, combinação de trabalho autônomo e heterônomo e de tempo gasto em atividades não econômicas. Maneiras viáveis de produzir meios de vida não combinam com empregos mal remunerados exercidos em condições insalubres, com prestação inadequada de serviços públicos, como educação e saúde e de padrôes subumanos de moradia e alimentação.

No relatório de 2004 diz que as pessoas são as verdadeiras riquezas das naçóes e que na verdade, o objetivo básico do desenvolvimento é alargar as liberdades humanas.

Portanto, o processo de desenvolvimento deve expandir as capacidades humanas, aumentando o leque de escolhas que as pessoas têm para viver, pois as pessoas são ao mesmo tempo beneficiárias desse desenvolvimento, mas agentes deste mesmo desenvolvimento e da mudança que provocam. Já que este processo deve beneficiar todos os indivíduos equitativamente e basear-se na participação de cada um deles no meio em que vivem.

No entanto, forçoso reconhecer que estamos diante de um desafio enorme frente a uma crise ambiental e frente à imensa necessidade diária de desenvolvimento e crescimento econômico, já que nos faz pensar se há como harmonizar tais aspectos e se conviver em um ambiente ecologicamente equilibrado.

\section{Questão do Desenvolvimento Sustentável e da Harmonia com o Cresci- mento Econômico}

A situação que estamos vivendo em relação das açóes para a proteção do meio ambiente é chamada de crise ambiental, pois segundo estudiosos do tema como LEFF (2002), BOFF (2009), OST (1995) e SEN (2010) numa perspectiva holística significa não só as negatividades no meio ambiente natural, assim como a falência da forma de conduta do ser humano em face dos recursos naturais.

Enrique Leff sustenta que pela primeira vez, que a crise ecológica não é resultado de uma transformação natural, pois envolve transformaçóes de natureza metafísica, filosófica, ética, científica e tecnológica. Para o autor, a solução para referida crise passa pelo 
questionamento epistemológico do pensamento pautado nos pilares da uniformidade e homogeneidade (LEFF, 2002, p. 194).

A crise ambiental trata-se, portanto, de repensar as transformaçóes do meio ambiente numa perspectiva complexa, considerando os conhecimentos e saberes arraigado também nas cosmologias, mitologias, ideologias e saberes práticos que compóem a civilização contemporânea (LEFF, 2002, p. 196).

Assim, diante das proporçóes dessa crise ambiental surgem algumas alternativas de congregar esses fatores no sentido de combatê-la e de resgatar valores relacionados à defesa da vida. Dentre tais alternativas, nota-se a via do chamado desenvolvimento sustentável, através do qual se defende a necessidade de se buscar formas de efetivar a ideia da máxima compatibilização nas relações entre o ser humano e a manutenção de seu meio, mostrando-se de grande relevância, nesse sentido, as iniciativas para combater o conjunto de negatividades ocasionadas pelo modo de produção atualmente vigente.

A ideia do conceito de desenvolvimento sustentável ganhou uma dimensão global através do Relatório Brundtland, em 1987, da Comissão Mundial sobre o Meio Ambiente e Desenvolvimento. Esse Relatório conhecido como "Nosso Futuro Comum” determinou que da expressáo "desenvolvimento sustentável" depreende-se que a fruição dos recursos naturais pela presente geração, não deve prejudicar o mesmo direito das geraçôes futuras. A ideia de sustentabilidade a ser empregada remeterá à "noção de uma gestão ambiental não apenas no espaço, mas também no tempo” (SILVA, 2004, p. 81).

É essa ideia trazida pelo desenvolvimento sustentável que se pauta a preocupação com as políticas socioambientais, uma vez que os sentidos desse termo (socioambiental) apontam para a "inevitável necessidade de procurar compatibilizar as atividades humanas em geral com o crescimento econômico em particular - com a manutenção de suas bases naturais, particularmente com a conservação ecossistêmica” (VEIGA, 2007, p. 91).

Com isso, nota-se que a construção de políticas públicas em harmonia com o socioambiental deverá levar em conta as atividades humanas de forma que sejam incluídos os distintos modos de vida existentes sob o mesmo ordenamento jurídico, nesse campo, podem-se incluir todos, principalmente os povos tradicionais.

Portanto, a proteção dos recursos naturais ainda encontra obstáculos na forma como se desenvolvem as relaçóes de produção vigentes (FRACALANZA, 2005), bem como na dificuldade e complexidade na realização de uma exploração de recursos que observe os princípios do desenvolvimento sustentável, surgindo como problemática a vasta gama de tentativas de rever o comportamento da humanidade em face de seu trato para com o meio ambiente.

Por isso, a cultura desenvolvimentista que se presencia baseia-se, primordialmente num ideal de crescimento econômico incompatível com a realidade fática das sociedades e dos recursos que poderiam ser disponibilizados para tanto. 
Lutzenberger (2000, p. 10) exemplifica a questão do desenvolvimento e crescimento econômico com a dificuldade de harmonização de sustentabilidade ao sustentar que "o simples dogma básico do pensamento predominante, que diz que uma economia tem que crescer sempre, já é um absurdo. Nada pode crescer sempre, muito menos num espaço limitado", demonstrando o entendimento de que o crescimento econômico não deve prevalecer acima dos valores sociais que o sustenta. A busca pelo desenvolvimento, igualmente, não será saudável se não levar em conta essa necessidade: o resgate a respeito das mudanças que se buscam através dele.

Amartya Sen, em sua obra "Desenvolvimento como Liberdade" contribui de forma valiosa para o estabelecimento de uma visão de desenvolvimento mais voltada ao atendimento das necessidades sociais, o mais próximo possível daquela terceira forma de conceber a ideia desenvolvimentista proposta por Veiga:

[...] atenta-se particularmente para a expansão das "capacidades" das pessoas de levar o tipo de vida que elas valorizam - e com razão. Essas capacidades podem ser aumentadas pela política pública, mas também, por outro lado, a direçáo da política pública pode ser influenciada pelo uso efetivo das capacidades participativas do povo. Essa relação de mão dupla é central na análise aqui apresentada. (...). O êxito de uma sociedade deve ser avaliado, nesta visão, primordialmente, segundo as liberdades substantivas que os membros dessa sociedade desfrutam (...). Ter mais liberdade melhora o potencial das pessoas para cuidar de si mesmas e para influenciar o mundo, questóes centrais para o processo de desenvolvimento (SEN, 2010, p. 33).

Com isso, ao observar-se a falta ou deturpação da consideração dos valores norteadores das atividades humanas, na ideia de Amartya Sen, é oferecida uma alternativa coerente rumo a uma nova concepçấo dos valores caros à humanidade. Mais do que pensar a questão do desenvolvimento como o aumento do desempenho econômico de determinado Estado, é preciso pensar, antes, no oferecimento de oportunidades às pessoas de desenvolverem suas capacidades, de acordo com o estilo de vida que julgarem adequados às suas necessidades.

Portanto, especificamente, ao pensar no trato do ser humano para com o meio ambiente, deve-se buscar a observância dessa mesma liberdade. Uma vez que sejam recuperados o sentido do vinculo e do limite, sabiamente relembrados por Ost (1995), o ambiente será visto como algo inseparável da essência humana e, portanto, necessário à plena realização de suas capacidades.

No entendimento de Sen e Kliksberg, a noção de desenvolvimento sustentável trazida pelo Relatório Brundtland (1987) estaria sendo errado por desconsiderar o conjunto de valores que devem ser observados além das necessidades econômicas: 


\begin{abstract}
"ver as pessoas somente em termos de suas necessidades pode nos proporcionar uma visão um tanto acanhada da humanidade... não somos apenas pacientes, cujas necessidades exigem atenção, mas também agentes, cuja liberdade de decidir quais são seus valores e como buscá-los pode estender-se muito além da satisfação de nossas necessidades" (SEN e KLIKSBERG, 2010, p. 65).
\end{abstract}

Importante salientar, que enquanto outras análises sobre desenvolvimento se restringir ao universo do poder do Estado e da política sem a participaçáo da sociedade, sempre se estará diante de seres humanos sem liberdade, tal como lembra oportunamente Amartya Sen (2000), para quem a liberdade é central no processo de desenvolvimento, pelo fato de implicar na assimilação de uma razão avaliatória, que se dá pela verificação do aumento das liberdades das pessoas; e pela razáo de eficácia, que ocorre com a realizaçáo do desenvolvimento, dependente da livre condição de agente das pessoas.

Portanto, as críticas contra a noção de desenvolvimento convergem, de forma geral, à necessidade de humanizar esse entendimento, tornando o desenvolvimento um ideal mais compatível com a condição humana.

(...) desenvolver significa tirar o invólucro, descobrir o que estava encoberto; envolver significa meter-se num invólucro, comprometer-se. Desta forma, poderíamos dizer que desenvolver uma pessoa ou comunidade significa retirá-la do seu invólucro ou contexto ambiental; descomprometê-la com o seu ambiente (VIANA, 2006, p. 43).

Essa ideia corrobora os autores citados anteriormente tendo em vista que defende que as pessoas devem pretender chegar ao desenvolvimento através do exercício de suas potencialidades, envolvendo-se com os valores que considerarem importantes, incluindose, indubitavelmente, um tratamento adequado para com o ambiente que lhe circunda, tendo em vista que este compóe a unidade da existência e condição necessária à realizaçáo dessas potencialidades.

Urge aprender a entender o sentido de vínculo e de limite sobre o qual nos alerta François Ost que unem ser humano e meio ambiente. Do contrário, a natureza seguirá apenas o insustentável caminho de fonte inesgotável de recursos e depositária de resíduos.

Nessa possibilidade em relação ao Brasil quanto ao desenvolvimento sustentável, Sachs lembra que o Brasil possui o cenário ideal para que seja possível a concretização do princípio:

O Brasil é um país abençoado com a maior biodiversidade e a maior floresta tropical do mundo, amplas reservas de terras cultiváveis, boa disponibilidade de recursos hídricos na maior parte do território, climas favoráveis à produção vegetal (o sol é e sempre será nosso), gente disposta 
a trabalhar a terra [...] e excelentes agrônomos e biólogos. (SACHS, 2004, p. 106)

Portanto, quando se observa a exposição do autor, bem como o ideal de sustentabilidade apregoado nacional e internacionalmente, é possível inferir que no Brasil naturalmente haveria subsídios para a efetivação de um desenvolvimento pautado do conceito de sustentabilidade: o atendimento das necessidades das presentes geraçôes sem comprometer as geraçóes futuras (na perspectiva do Relatório Brundtland) ou como aquele defendido pelo próprio Sachs. Em sua visão, o desenvolvimento deve ser pautado em cinco pilares: a) social; b) ambiental; c) territorial; d) econômico e c) político.

\section{Dificuldades de Aplicação do Desenvolvimento Sustentável}

Os conceitos doutrinários e discussóes em todo o mundo acerca do que se entende sobre desenvolvimento sustentável levam a um denominador comum: a preocupação em harmonizar as necessidades econômicas e a preservação do meio ambiente.

A ideia de desenvolver e o crescimento econômico de maneira sustentável passaram a ser uma questão de sobrevivência para a própria humanidade.

Considerando a urgência da questão ambiental, hodiernamente o desenvolvimento sustentável, tende a ter contornos mais palpáveis, para tanto, foram traçados alguns objetivos para que o princípio se concretize.

Dentre os objetivos do desenvolvimento sustentável cita-se àqueles que formaram as diretrizes da $\mathrm{RIO}+20$, vejamos:

1 - erradicar a pobreza extrema, inclusive a fome;

2 - alcançar o desenvolvimento dentro dos limites planetários;

3 - assegurar o aprendizado efetivo de todas as crianças e jovens para a vida e a subsistência;

4 - alcançar a igualdade de gêneros, a inclusão social e os direitos humanos;

5 - alcançar a saúde e o bem-estar para todas as idades;

6 - melhorar os sistemas agrícolas e aumentar a prosperidade rural;

7 - tornar as cidades mais inclusivas, produtivas e resilientes;

8 - refrear as mudanças climáticas e garantir energia limpa para todos;

9 - proteger os serviços ecossistêmicos, a biodiversidade e a boa gestão dos recursos naturais;

10 - ter uma governança voltada para o desenvolvimento sustentável.

Essas metas, mesmo que não concretas com prazos de cumprimento, os objetivos traçados demonstram o novo sentido que se quer dar as práticas até então adotadas. 
Para que o mundo possa de fato comprometer-se nos níveis econômico, político e social com a preservação dos recursos naturais, essas metas devem ser levadas em consideração.

O desenvolvimento econômico é muito importante para os países mais pobres, mas o caminho a seguir não pode ser o mesmo adotado pelos países industrializados, por vários motivos, mas, principalmente porque o meio ambiente não resistiria a um processo táo devastador quanto o modelo adotado pelos países industrializados.

Por conta disso, a complexidade ambiental não é a ecologização do mundo, pois o pensamento complexo desborda a visão cibernética de uma realidade que se estrutura e evolui através de um conjunto de inter-relaçóes e retroalimentaçóes, como um processo de desenvolvimento que vai da auto-organização da matéria à ecologização do pensamento (MORIN, 1986).

Complementa Prigogine (1997) que a complexidade não é somente a incorporação da incerteza, do caos e da possibilidade na ordem da natureza, deve ser algo concreto que se aplique de maneira uniforme e efetiva.

Leff afirma que para todos tem que haver educação para se chegar ao resultado que se espera.

Por fim, é preciso refletir sobre o alerta de Samuel Benchimol (2002, p. 25):

O futuro não acontece por si mesmo. O seu fabrico é produto da ação planejada, da inovação da iniciativa privada, do desejo político e da sociedade de criar um horizonte de vida, trabalho e bem estar, que contemple a todos sob o pálio da justiça e da fraternidade.

Acontece que infelizmente, denota-se a ineficácia global do direito internacional do desenvolvimento sustentável, em decorrência, principalmente, das normas internacionais caracterizarem-se como normas não cogentes, ou seja, normas que exigem um cumprimento tão somente moral (MORENO, 2002, p.797).

O princípio ao desenvolvimento sustentável é configurado como uma normativa vaga e por tal motivo acata-se a sugestão de Herrero (2000, p.101) no sentido de ser necessário estabelecer a relação de um princípio vago a pontos referenciais, em função de diferentes princípios, valores e escalas. A base teórica, portanto, fornece os dados elementares à compreensão da intenção conservacionista às geraçôes futuras.

Na prática, para cada segmento tomado como referência necessitará de uma análise multidisciplinar, local e temporal, a fim de se elaborar um parecer final quanto aos graus de sustentabilidade e caminhos ou meios para seu alcance.

Desse modo, cada país deverá tomar a iniciativa na criação de mecanismos jurídicos próprios, de acordo com as normativas internacionais, para dar aplicabilidade e fazer 
inserir em seus ordenamentos jurídicos nacionais, o princípio do desenvolvimento sustentável.

Desenvolver de maneira sustentável é um desafio, mas um desafio possível se houver vontade política e o comprometimento de toda a sociedade em adotar e incentivar práticas sustentáveis.

\section{A Problematização em Relacao aos Povos Tradicionais}

Em relação aos povos tradicionais, verificamos que o crescimento econômico vem trazer grandes impactos para a realidade desses povos, pois os mesmos muitas vezes devem sair de suas moradias e locais tradicionalmente ocupados para dar lugar ao desenvolvimento.

Quando faz uma análise das crises postas à humanidade, bem como as respostas ofertadas a elas, é possível notar alguns pontos de convergência como a necessidade da revisão do modo de produção vigente, bem como das bases éticas que sustentam as relações da sociedade entre si mesma e com o entorno.

Tendo em vista as consequências dessas bases, que acabavam atendendo a interesses voltados para somente a manutenção do sistema através do lucro, nota-se a premente necessidade de retorno à consideração do bem-estar da sociedade por meio de um consenso mínimo, a que Leonardo Boff (2009) que se refere, na obra "Ethos mundial: um consenso mínimo entre os humanos".

Nesse sentido, cabe destacar que já é possível observar o atendimento à construção desses Ethos. Um dos exemplos mais significativo deste esforço na América Latina remete às novas constituiçóes da Bolívia e do Equador, que consagram esse consenso como a Suma Qamaña, ou "vivir bien” ou "bien vivir".

A Constituição Boliviana (2009) traz em seu texto a noção de "vivir bien" como princípio ético-moral da sociedade plural, fazendo dela o objetivo primordial da sociedade.

Com isso, a educação, o modelo econômico e a eliminação da pobreza deverão estar orientados para o "vivir bien".

Em relação à natureza, é possível observar a defesa de sua gestão respeitando a soberania e o interesse do povo. Também é possível observar nessa Constituição a remissão expressa à observância do ideal de desenvolvimento sustentável e de respeito à natureza.

A Constituição Boliviana prevê, ainda, a soberania dos povos indígenas sobre os recursos existentes em seus espaços, segundo as normas legais para sua proteção, mas utilizando-se de suas próprias normas e formas harmônicas de relação com a natureza.

Sem ser diferente a Constituição equatoriana, utiliza-se de um termo parecido, o "buen vivir" também como princípio a ser observado, mas elenca uma série de direitos 
necessários à sua constituição. Estabelece, ainda, que as pessoas poderão beneficiar-se dos recursos naturais de acordo à noção desse "buen vivir" e que as políticas públicas de modo geral deverão ser orientadas por ela.

A mediação de conflitos deve ser orientada pelo "buen vivir", assim como as formas de desenvolvimento, que também deverão respeitar as diferenças. Também é possível observar nessa Constituição a presença de um rol de deveres do Estado, das pessoas individualmente e das sociedades organizadas para a consecução do chamado "buen vivir". Além disso, há todo um título da Constituição dedicado ao estabelecimento de como o Estado, juntamente com a sociedade deverão alcançar esse ideal.

Com isso, é importante pensar que as experiências que se tem buscado espaço num mundo adepto da lógica mercadológica, mas que busquem dar a ele uma nova forma possa ajudar na construçáo de uma sociedade mais justa, equilibrada, e que busque resguardar os direitos socioambientais aos povos altamente agredidos e desrespeitados, a partir de uma visão realmente abrangente, integrada e conciliadora.

Por este motivo, é de extrema importância se observar e tentar extrair exemplos que vem mudando a visão de direitos e o respeito aos povos tradicionais em relaçáo aos entraves e direitos protegidos diante do crescimento econômico e o desenvolvimento, visando atingir a tão debatida concretização do mais próximo possível à ideia de desenvolvimento sustentável.

\section{Conclusões}

A crise ambiental que passa o planeta terra em torno dos recursos naturais afeta a sociedade em seu sentido mais amplo e, em consequência também os povos tradicionais, exercem pressóes e influências na reconstrução do Direito como ciência que vem regular essa crise.

O papel das instituiçôes jurídicas, nesse sentido, é para a produção de respostas ao embate entre desenvolvimento e crescimento econômico e a preservação ambiental, o que é de fundamental importância para gerar estruturas que permitam a gestão dos recursos naturais em face das necessidades da sociedade e dos problemas ambientais de diversos alcances.

As questóes relativas aos desequilíbrios socioambientais, portanto, remetem, a um só tempo, às questóes econômicas, culturais, sociológicas e ecológicas, que precisam ser observadas pelo Direito enquanto ciência e enquanto norma aplicada.

Nesse sentido, várias são as alternativas que tentam congregar tantos fatores, muitas vezes controversos. Assim, no âmbito teórico, a via proposta pelo desenvolvimento sustentável parece apontar de forma mais clara para este caminho e, por tal motivo, tem 
tomado destaque como norte pelo qual tem se pautado as políticas ambientais instituídas no âmbito do Direito, politicas essas que devem ser urgentes para não gerar maiores problemas tanto à sociedade como um todo, como aos que tanto já sofreram com esses problemas ambientais, os povos tradicionais.

Essa nova forma de ver a realidade, sobretudo, dos povos tradicionais, passa por uma superação das concepçóes centradas na exploração predatória e sua (re)definição a partir da inserção de uma nova forma de ver a relação homem/natureza que se depreende, não de uma forma de desenvolvimento fundada na mudança dos processos decisórios que não se limitem aos espaços políticos tradicionais, mas na inclusão de atores referentes pelo envolvimento sustentável (VIANA, 1999).

\section{Referências}

BENCHIMOL, Samuel. Amazônia: Formação social e cultural. Manaus: Valer, 1999.

BENCHIMOL, Samuel. Desenvolvimento Sustentável da Amazônia: Cenários, perspectiva e indicadores. Manaus: Editora Valer e Universidade do Estado do Amazonas, 2002.

BOFF, Leonardo. Ethos mundial: um consenso mínimo entre os humanos. Rio de Janeiro: Record, 2009.

BOLÍVIA, Constituición Politica Del Estado. Disponível em: <http://www.transparencialegislativa.org/wpcontent/uploads/2013/04/Constitucio\%CC\%81n-Bolivia. pdf>. Acesso em: 06.04.2015.

BRASIL, Fundação Amazonas Sustentável. Disponível em: <http://www.estadao.com. $\mathrm{br} /$ noticias/vidae,onu-lanca-rascunho-de-objetivos-de-desenvolvimento-sustentavel,1029869,0.htm>. Acesso em: 06.04.2015.

BRASIL, Diretrizes do texto da Rio+20. Disponível em: <http://revista.brasil.gov. br/especiais/rio20/entenda-a-rio20/desenvolvimento-sustentavel>. Acesso em: 06.04.2015.

CAPRA, Fritjof. As Conexóes Ocultas: Ciência para uma vida sustentável. Tradução Marcelo Brandão Cipolla, São Paulo: Cultrix, 2002.

FONSECA, Ozório J. M. Pensando a Amazônia. Manaus: Valer, 2011.

FRACALANZA, Ana Paula. Água: de elemento natural à mercadoria. Revista Sociedade \& Natureza. Uberlândia: Editora, v. 17, 21-36, dezembro 2005.

FURTADO, Celso. Formação Econômica do Brasil. Companhia Editora Nacional, $14^{\mathrm{a}}$ ed., S. Paulo, 1976. 
HERRERO, Luis M. Jiménez. Desarrollo Sostenible. Transición hasta lacoevolución global. Madrid: Pirámide, 2000.

LEFF, Enrique. Epistemologia ambiental. 2ed. São Paulo: Cortez, 2002.

LEFF, Enrique. Saber Ambiental: sustentabilidade, racionalidade, complexidade, poder. Tradução de Lúcia MathildeEndlich Orth. Petrópolis, RJ: Ed. Vozes, 2001.Via Livros em PDF. Acesso em 06.04.2015.

LUTZENBERGER, José. Manual de ecologia: do jardim ao poder. v. 1. Porto Alegre: L\&M, 2006.

MEIRELlES FILHO, João Carlos. O livro de ouro da Amazônia. 5.ed. Rio de Janeiro: Ediouro, 2006.

MORENO, Javier Caño. Desarrollo sostenible. In: EstudiosJuridicosen Memoria de JoseMaria Lindón. Bilbao, Espanha: Universidad de Deusto, 2002. p.791-204.

OST, Françoais. A natureza à margem da Lei: a ecologia à prova do direito. Lisboa: Instituto Piaget, 1995.

PORFIRIO JUNIOR, Nelson de Freitas. Responsabilidade do Estado em face do Dano Ambiental. São Paulo: Malheiros Editores, 2002.

SACHS, Ignacio. Caminhos para o Desenvolvimento Sustentável. Organização: Paula Yone Stroh. Rio de Janeiro: Garamond, 2009.

SACHS, Ignacy. Desenvolvimento: includente, sustentável, sustentado. Rio de Janeiro: Garamond, 2004.

SEN, Amartya. Desenvolvimento como liberdade. São Paulo: Companhia das Letras, 2010. .Sobre ética e economia. São Paulo: Companhia das Letras, 1999.

SEN, Amartya; KLIKSBERG, Bernardo. As pessoas em primeiro lugar: a ética do desenvolvimento e os problemas do mundo globalizado. São Paulo: Companhia das Letras, 2010.

SILVA, Solange Teles. Princípio da precauçáo: uma nova postura em face dos riscos e incertezas científicas. In: VARELLA, Marcelo Dias e PLATIAU, Ana Flávia Barros (Orgs.). Princípio da precaução. Belo Horizonte: Del Rey, 2004.

SIRVINSKAS, Luís Paulo. Manual de Direito Ambiental. $11^{\text {a }}$ ed. São Paulo: Saraiva, 2013.

VEIGA, José Eli. A emergência socioambiental. São Paulo: Editora Senac São Paulo, 2007. .Desenvolvimento sustentável: o desafio do século XXI. Rio de Janeiro: Garamond, 2008.

VIANA, Virgílio. As florestas e do desenvolvimento sustentável na Amazônia. Manaus: Valer, 2006. 
Envolvimento sustentável e conservação das florestas brasileiras. Ambiente e Sociedade - ano II - $\mathrm{n}^{\circ} 5-2^{\circ}$ semestre de 1999.

VIANNA, José Ricardo Alvarez. O Direito Ambiental e o princípio do desenvolvimento sustentável. Jus Navigandi, Teresina, ano 7, n. 57, 1 jul. 2002. Disponível em: <http://jus2.uol.com.br/doutrina/texto.asp?id=2974>. Acesso em: 06.04.2015. 